\title{
EFFICACY OF SCREENING METHODS USED IN BREEDING FOR BLACK POD DISEASE RESISTANCE VARIETIES IN COCOA
}

\author{
D. NYADANU, M.K. ASSUAH, B. ADOMAKO, YAW OPOKU ASIAMA ${ }^{1}$, I.Y. OPOKU \\ and Y. ADU-AMPOMAH \\ Plant Pathology Division, Cocoa Research Institute of Ghana \\ ${ }^{1}$ Department of crop science, University of Cape Coast, Cape Coast, Ghana
}

(Received 13 August, 2009; accepted 28 November, 2009)

\begin{abstract}
Black pod is an important fungal disease of cocoa (Theobroma cacao L.) that causes severe yield losses. The disease affects the pods, beans, flower cushions, leaves, stems and roots. The objective of this study was to evaluate the efficacy of resistance screening methods used in breeding black pod disease resistance in cocoa. The resistance of cocoa leaves and pods to Phytophthora palmivora was investigated in twenty five international genotypes of cocoa in five laboratory experiments and a field observation at the Cocoa Research Institute of Ghana. A significant clonal difference for leaf and pod resistance was observed at penetration and post-penetration stages of infection. Correlation between resistance of leaves and pods was positive and significant at both penetration and post-penetration stages of infection. The occurrence of such a characteristic of cocoa leaf suggests the value of use of leaves of cocoa seedlings for the prediction of pod resistance to black pod disease. The reliability of the tests was evaluated by correlating results of the inoculation tests with the level of field infection. These correlations were generally positive and significant, both for detached pod and leaf tests. The high positive correlation between detached leaves and pods and natural Phytophthora pod rot infection in the field showed that detached organs can be used for prediction of resistance in the field. Overall, for the convenience of operations and reliability of results, leaf disc test was the best screening method and was also time saving. Clones SCA 6, T85/799, LAF1, ICS 1 and GU 225V were noted to be promising for breeding against black pod disease. The susceptible clones were MO 20, T79/501, VENC 4-4, PA 120 and MOCORONGO.
\end{abstract}

Key Words: Phytophthora palmivora, penetration resistance, Theobroma cacao

\section{RÉSUMÉ}

La gousse noire est une maladie fongique importante du cacao (Theobroma cacao L.) qui cause des pertes de rendement énormes. La maladie affecte les cabosses, des fèves, des coussins de fleurs, feuilles, les tiges et les racines. L'objectif de cette étude était d'évaluer l'efficacité des méthodes de sélection utilisées dans la résistance aux maladies de gousse noir dans le processus d'amélioration du cacao. La résistance des feuilles et gousses du cacao au Phytophthora palmivora avait fait l'objet d'une investigation sur vingt-cinq génotypes internationaux du cacao dans cinq expériences de laboratoire et dans une observation de champ à l'Institut de Recherche sur le Cacao au Ghana. Une différence clonale significative pour la résistance de la feuille et de la gousse avait été observée aux stades de pénétration et post-pénétration de l'infection. La corrélation entre la résistance des feuilles et les gousses était positive et significative aussi bien au stade de pénétration qu'au stade de post-pénétration au cours de l'infection. L'apparition d'une telle caractéristique de la feuille du cacao suggère la valeur de l'utilisation des feuilles de plantules du cacao dans la prédiction de la résistance de gousse aux maladies de gousse noire. La fiabilité des tests avait été évaluée par la corrélation des résultats des tests d'inoculation avec le degrée d'infection du champ. Ces corrélations étaient généralement positives et significatives, tant pour la gousse détachée que pour les tests de la feuille. La haute corrélation positive entre les feuilles détachées et les gousses, ainsi que l'infection de la pourriture naturelle des gousses par Phytophthora dans le champ avaient montré que les organes détachés 
peuvent être utilisés pour la prédiction de la résistance au champ. En général, pour la commodité des opérations et la fiabilité des résultats, le test de disque de feuille a été la meilleure méthode de sélection et avait été également économiser du temps. Clones SCA 6, T85/799, LAF1, ICS 1 et GU 225V s'étaient révéles être les clones prometteuses pour l'hybridation contre la maladie de la gousse noire. Les clones sensibles étaient MO 20, T79/ 501, VENC 4-4, PA 120 et MOCORONGO.

Mots Clés: Phytophthora palmivora, résistance à la pénétration, Theobroma cacao

\section{INTRODUCTION}

Black pod is an important fungal disease of cocoa that causes very serious losses. The disease affects the pods, beans, flower cushions, leaves, stems and roots. Opoku et al. (1999) reported two species of Phytophthora viz. Phytophthora palmivora and Phytophthora megakarya as the causal agents of black pod disease in Ghana. $P$. megakarya is of more recent occurrence in Ghana and is the most destructive of the two pathogens. In areas invaded by $P$. megakarya, pod losses increased from $15 \%$ in the presence of $P$. palmivora to $30-35 \%$ as a result of $P$. megakarya infection (Kebe et al., 1999). Adomako (2007) reported that yield loss in cocoa was largely due to black pods representing $64.1 \%$ of total yield loss. In 1985, worldwide losses due to black pod were estimated at $£ 1,540$ million (Evans and Prior, 1987).

On pods, the predominant symptom is a brownish or black lesion on the husk, leading to blackening and rotting of the pod. On stems, the symptoms appear as cankers (Opoku et al, 2007). Even though damage due to the leaf and root infections by Phytophthora species are difficult to estimate, their effect on the health and productivity of cocoa trees are known to be significant.

The control of black pod disease is, therefore, a major challenge for world cocoa cultivation and selection of resistant materials is underway many producing countries to control Phytophthora. According to Tan and Tan (1990), several methods have been adopted by farmers to control diseases caused by Phytophthora species in cocoa, of which use of copper-based fungicides is the most predominant. Although this is reasonably effective, the high cost of chemical control in Africa poses a serious challenge to peasant farmers who produce over $50 \%$ of the world cocoa . Moreover, these chemicals are toxic to animals including man and, therefore, pose a great danger to peasant farmers most of whom are illiterates (Anon, 1995).

Breeding for resistance to black pod disease has been long regarded as the most economical; environmentally friendly and effective control method (Iwaro et al., 2004). Along this premise, genetic studies have shown that resistance to black pod attack is polygenically inherited and could be improved by recurrent selection (Iwaro et al., 1999). Field observations of the cocoa cultivars have shown consistent differences in levels of infection; although no selection has shown complete immunity, but sufficient variability for incorporation into breeding programmes. Adomako (2006) reported significant differences between cocoa genotypes in the levels of black pod disease in two field trials.

In breeding for resistance to black pod, there is the need to screen the progenies in order to select the most resistant plants. However, progress in breeding has been hampered by lack of effective screening methods to identify genotypes with superior abilities to be incorporated into breeding programmes. Selection of resistant material in the field and all the known tests for resistance based on pod inoculation necessitates waiting until a tree bears pods before its level of resistance to black pod infection can be determined. These methods, therefore, do not offer a quick means of breeding for resistance. Consequently, tests at the seedling stage that provide information about pod resistance are earnestly needed to save time and cost.

However, the correlation between the reactions of detached leaves and pod tests to $P$. palmivora infection is not well understood and utilised. Wheeler (1992) emphasized the need to understand the relationship between pod resistance and leaf resistance to $P$. palmivora 
and, the relationship between detached leaves and pod tests to $P$. palmivora infection in the field to expedite the screening of germplasm.

The objective of this study was, therefore, to evaluate the efficacy of resistance screening methods used in breeding black pod disease resistance in cocoa.

\section{MATERIALS AND METHODS}

Six screening methods were used to test for $P$. palmivora resistance in 25 cocoa genotypes. The six methods were: leaf disc test, punch inoculation leaf method, multiple point inoculation method of cocoa pods, stab inoculation method of cocoa pods, and natural field infection of cocoa pods. A comparison of results from these six methods of testing permitted the selection of the best screening method for cocoa breeding against black pod disease.

Experimental site. The experiment was conducted on-station in a cocoa clonal plot (0.6 ha) at the Cocoa Research Institute of Ghana (CRIG) in the eastern region of Ghana. The plot was established in 2001. Cocoa trees were planted in a randomised complete block design (CRD) with 5 replications was $2.5 \mathrm{~m} \times 2.5 \mathrm{~m}$, and the crop was grown under shade trees with uniform and optimal cover (approximately $50 \%$ of the solar radiation passed through the canopy). No fertilisers were applied. Regular pruning was performed on the exceeding plagiotropic and orthotropic branches, along with the removal of parasitic epiphytes and chupons.

Cocoa genotypes. The genetically diverse set of 25 cocoa clones used for this study represent the international clone trials supported by the CFC/ICCO/Biodiversity project being evaluated in Ghana. Each clone was represented by ten trees in each replication. They included: PA 120, MOCORONGO, LECTEEN 37f, ICS 43, SPEC 54i, EQX 78, EET 59H, PA 107, LECTEEN 37f, SCA6, LAF 1, T85/799, AMAZ 15-15, EQX 3360-3, IFC 5, IMC 47, PA150, UF 676, VENC 4-4, ICS1, BE 10, MO 20, MAN 15-2, GU 225V and T79/501.

Isolation of Phytophthora species from black pod infected pods from the field. Isolation of Phytophthora species was done from naturally infected pods collected from the K-5 extension plot on which the 25 genotypes were planted. The diseased pods were washed with distilled tap water and blotted dry. The pods were then surface sterilised with $70 \%$ ethanol. The infected parts of the pods were cut into $5 \mathrm{~mm}$ segments. The segments were then plated on carrot agar medium. All inoculated plates were incubated for 3 days on a laboratory bench. Plates were observed daily for fungal growth from tissue segments. Fungal growths from tissue segments were transferred onto another carrot agar medium to obtain pure culture of the isolated fungi. Emergent colonies were examined under light microscope for identification of the Phytophthora specie.

Based on the characteristic 'seaweed' odour of the infected pod, growth of isolate on carrot agar medium, sporangial shape and size and pedicel length; the organism was identified as $P$. palmivora. The isolate was grown on a carrot agar medium and from a ten-day-old culture, a zoospore suspension was obtained by inundating each culture plate ( $9 \mathrm{~cm}$ diameter) with $10 \mathrm{ml}$ sterile distilled water. The plates with the sterile distilled water was then refrigerated for 25 min. at $5^{\circ} \mathrm{C}$ and transferred into an incubator for 25 minutes. The distilled water was poured into a beaker as a zoospore suspension.

The concentration of zoospores were determined with a hemacyatometer and adjusted to 200,000 per $\mathrm{ml}$. This concentration of inoculum was reported as optimum in similar inoculations conducted by several workers ( Sitapai, 1989; Screenivasan, 1995; Okey, 1996). The pathogenicity of the isolate was maintained by regular inoculation in the laboratory of green mature cocoa pods, followed by re-isolation on carrot agar medium.

Field leaf sampling. The new flushes from bud break of the clones were tagged to obtain average ages of the leaves for each experiment. For each of the inoculation series, leaves were collected from all the 25 clones in each replication. In the field, 15 leaves were harvested from each clone in each replication. The average ages of the leaves for each treatment were established by following the growth of young flushes from bud break in the field. After collecting the mature leaves, they 
were placed in labelled polyethylene bags into which a few drops of distilled water were sprayed before hand. The bags were then kept in the dark till the next morning to minimise effect of leaf sampling time that may occur with large time lapses between harvesting of leaves (Tahi, 2003). The leaves were washed thoroughly with tapwater, blotted dry with Whatman number 3 paper and then surface sterilised with $70 \%$ ethanol.

Detached leaf inoculation tests. The detached leaf inoculations used were the leaf disc test, multiple point inoculation of leaf and punch inoculation of leaf.

Assessment of leaf resistance to $P$. palmivora by the leaf disc test. Leaf disc inoculation as described by Nyasse et al. (1995) was carried out. Sixteen leaf discs of $1.5 \mathrm{~cm}$ diameter from each clone in a replication were made with a cork borer, totaling to $80(5 \times 16)$ discs per clone. Leaf discs were placed with their abaxial surface upwards on wetted plastic foam in five trays of $70 \mathrm{~cm}$ long, $60 \mathrm{~cm}$ wide and $15 \mathrm{~cm}$ high. Discs belonging to the same replication were randomly arranged in groups of 25 within each tray, giving 16×25 $=400$ discs per tray.

Inoculation was carried out on the same day, after preparation of leaf discs. After the concentrations of zoospores were determined with a hemacyatometer and adjusted to 200,000 per ml, droplets of $10 \mathrm{ml}$ were placed on each disc. The discs were incubated at room temperature $\left(25^{\circ} \mathrm{C}\right)$ in plastic trays lined with moist plastic foam and covered with another plastic tray in the laboratory to prevent direct sunlight until observations were made.

On the sixth day of incubation, disease severity symptoms were recorded using a 0-5 assessment scale developed by Nyasse et al. (1995). $0=$ absence of symptoms, $1=$ very small necrotic spots, $2=$ larger number and size of necrotic spots, $3=$ coalescence of brown spots into medium-sized, $4=$ large uniform brown lesions and $5=$ very large brown lesions, often expanding outside the area covered by the inoculum droplet.

Assessment of leaf resistance to $P$. palmivora at the penetration level of infection. Leaf resistance at the penetration stage of infection was assessed with the tissue-paper mount method of inoculation (Iwaro et al., 1997a).

Mature leaves at the interflush-2 stages as described by Greathouse et al. (1991), were surface sterilised with $70 \%$ alcohol and rinsed in sterile distilled water. The surface sterilised leaves were then placed in plastic trays lined with moist plastic foam, with the abaxial surface facing upwards. From each clone in a replication, 5 leaves were placed in one tray. Tissue paper-mount inoculation of the leaf samples was done by applying a 30iL drop of zoospore suspension on the leaf surface. Then, a piece of tissue paper (area: $1 \mathrm{~cm}^{2}$, thickness: $0.23 \mathrm{~mm}$ ) was placed on top to allow a uniform spread of the zoospore suspension within the area covered by the tissue paper. A leaf from each clone was inoculated with sterile distilled water as a control in each experiment.

The 25 clones were arranged in a randomised complete block design with five replications. The set up was then incubated at room temperature $\left(25^{\circ} \mathrm{C}\right)$ in plastic trays lined with moist plastic foam and covered with another tray. After 6 days of incubation, the tissue-paper-mounts were carefully removed and the penetration resistance was determined by counting the number of lesions.

\section{Assessment of leaf resistance to $P$. palmivora at the post-penetration level of infection.} Assessment of leaf resistance at the postpenetration stage of infection was based on the punch inoculation method (Iwaro et al., 1997b).The area of lesions formed was used as an indication of post-penetration resistance. A 4 $\mathrm{mm}$ diameter hole was punched in the leaf lamina and was covered at the adaxial surface with a spot plaster. The hole in the abaxial surface was filled with a $4 \mathrm{~mm}$ diameter filter paper disc previously immersed in a 200,000 zoospores $\mathrm{ml}^{-1}$ suspension. A leaf from each clone was inoculated with sterile distilled water instead of zoospore suspension as a negative control.

Inoculated leaves were arranged in a CRD with five replications. They were incubated at room temperature $\left(25^{\circ} \mathrm{C}\right)$ in trays lined with moist plastic foam and covered with another tray. After incubation for six days, the lesion areas on leaves were cut and assessed for lesion size with a leaf 
area meter (MK2, Delta T services, Burnwell, and Cambridge, England).

Sampling of pods from the field. Mature unripe pods of sizes similar to those of ripe ones at approximately four months old, were used as test samples. Pods were harvested with care and kept in labeled plastic bags. The pods were covered with cotton wool in order to avoid surface damage which occurs when many pods are kept together in close contact with each other. The harvested cocoa pods were washed thoroughly with tapwater and blotted dry with Whatman Number 3 paper. They were then surface sterilised with $70 \%$ ethanol.

\begin{abstract}
Assessment of pod resistance to $P$. palmivora at the penetration level. Resistance of pod at the penetration level was assessed using the multiplepoint inoculation (Iwaro et al., 1997b). The multiple point inoculation was performed on the pod surface, in which $10 \mu \mathrm{L}$ drops of inoculum were placed at 3 points along the ridges with a micropipette. A distance of about $3 \mathrm{~cm}$ was maintained between inoculated points to avoid merging of adjacent lesions.

A zoospore concentration of 200,000 per ml was used. Again, pods from each clone are inoculated with sterile distilled water instead of zoospore suspension as a negative control. The 25 clones were replicated five times with appropriate controls and arranged in a CRD. The pods were incubated at $25^{\circ} \mathrm{C}$ in a $40 \mathrm{~cm}$ x $60 \mathrm{~cm}$ transparent polyethene bags. A beaker of water was kept in the bag to provide adequate moisture with the mouth of the bag closed. After 6 days, pods were assessed for the number of established lesions and this number was used as an indication of penetration resistance.
\end{abstract}

Assessment of pod resistance to $P$. palmivora at the post-penetration level. Assessment of pod resistance at the post-penetration stage of infection was based on stab inoculation method (Iwaro et al., 1997b). The area of lesion formed was used as an indication of post-penetration resistance. For the stab-inoculation, a standard injury $4 \mathrm{~mm}$ in size was created on the pod surface with a cork borer. The wounded spot was inoculated with a piece of cotton wool previously immersed in a 200,000 zoospores $\mathrm{ml}^{-1}$ suspension and covered with a spot plaster.

Inoculated pods were arranged in a CRD with five replications and incubated at room temperature $\left(25^{\circ} \mathrm{C}\right)$ in $40 \mathrm{~cm} \mathrm{x} 60 \mathrm{~cm}$ transparent polyethylene bags. A beaker of water was again kept in the bag to provide adequate moisture with the mouth of the bag closed. After incubation for six days, the size of the established lesion was traced on a transparent paper. Lesion size was determined from brown paper cutouts trimmed to the size of each lesion and was measured with a leaf area meter.

Assessment of natural field infection of black pod disease. Natural pod infections in the field were collected from all the 25 clones in each replication, monthly from July to December, 2007. The diseased, wilted, damaged and ripened pods were removed each month. Pods infected by Phytophthora, Rodent damaged pods and healthy ripe pods were counted each month, and the completely rotten pods were removed after each harvesting. The percentages of pods affected by Phythophthora pod rot were estimated in relation to the total number of pods produced by the tree.

Data analysis. All the data obtained were analysed using the Genstart statistical software (Version 10.0) to perform analysis of variance. The residual plots were inspected to confirm data conformed to normality. The significance of mean differences among genotypes was evaluated at $\mathrm{P}<0.05$, using Tukey's Test. The relationships among leaf disc scores, field observation of $P$. palmivora infection, penetration and postpenetration reaction to $P$. palmivora infection in leaf and pod were tested by Spearman's Correlation Analysis. All analyses were based on repeated experimental data.

\section{RESULTS}

Clonal differences in leaf and pod resistance at the penetration stage of infection. Clonal differences in leaf and pod resistance at the penetration stage of infection are presented in Table 1 . The number of lesions obtained from the tissue-paper-mount test indicated significant 
TABLE 1. Clonal differences in lesion number and lesion size in both leaf and pod of cocoa

\begin{tabular}{|c|c|c|c|c|}
\hline \multirow[b]{2}{*}{ Clone } & \multicolumn{2}{|c|}{ Mean lesion number } & \multicolumn{2}{|c|}{ Mean lesion size $\left(\mathrm{cm}^{2}\right)$} \\
\hline & Leaf & Pod & Leaf & Pod \\
\hline PA120 & 40.96 & 10.52 & 47.46 & 140.88 \\
\hline MOCORONGO & 33.72 & 8.04 & 41.58 & 84.60 \\
\hline LECTEEN 37i & 15.96 & 7.64 & 32.52 & 44.84 \\
\hline ICS 43 & 18.80 & 7.88 & 39.20 & 52.70 \\
\hline SPEC 54i & 30.96 & 8.20 & 40.50 & 74.12 \\
\hline EQX 78 & 41.84 & 9.24 & 47.72 & 69.50 \\
\hline EET 59H & 13.28 & 5.52 & 23.92 & 35.41 \\
\hline PA107 & 13.92 & 6.84 & 23.08 & 34.32 \\
\hline LECTEEN $37 f$ & 16.52 & 7.16 & 30.62 & 64.38 \\
\hline SCA 6 & 6.68 & 2.28 & 4.50 & 13.08 \\
\hline LAF 1 & 12.32 & 5.52 & 12.24 & 21.29 \\
\hline T85/799 & 10.64 & 4.40 & 10.89 & 21.12 \\
\hline AMAZ 15-15 & 33.60 & 8.60 & 42.06 & 82.64 \\
\hline EQX 3360-3 & 16.84 & 6.88 & 30.50 & 42.15 \\
\hline IFC 5 & 13.40 & 6.00 & 22.90 & 150.74 \\
\hline IMC 47 & 37.48 & 8.36 & 46.66 & 83.12 \\
\hline PA 150 & 26.64 & 8.20 & 43.40 & 63.14 \\
\hline UF 676 & 18.16 & 8.04 & 35.88 & 53.06 \\
\hline VENC 4-4 & 43.76 & 10.00 & 47.14 & 95.50 \\
\hline ICS 1 & 11.44 & 5.16 & 10.86 & 23.08 \\
\hline BE 10 & 17.24 & 7.44 & 30.32 & 64.54 \\
\hline MO 20 & 44.96 & 13.40 & 67.14 & 162.66 \\
\hline MAN 15-2 & 21.32 & 8.24 & 37.24 & 59.06 \\
\hline GU 225V & 9.60 & 5.68 & 16.39 & 26.98 \\
\hline T79/501 & 44.28 & 11.08 & 59.55 & 161.09 \\
\hline LSD & 2.43 & 0.74 & 1.17 & 2.10 \\
\hline CV (\%) & 5.15 & 4.87 & 1.75 & 1.63 \\
\hline
\end{tabular}

differences $(\mathrm{P}<0.001)$ among genotypes in their reactions to $P$. palmivora at the penetration stage. The number of lesions among genotypes varied from 6.68 for SCA 6 , to 44.96 for MO 20. They were highest on leaves of MO 20, PA 120 , T79/501, EQX 78 and VENC4-4 and lowest on SCA 6, T85/799, ICS1, LAF 1 and GU 225V. In addition, the number of lesions on inoculated pods varied significntly among genotypes (Table 1). The number of lesions produced on pods of T79/501 and MO 20 were significantly large (11.08 and 13.40 , respectively) than for the other genotypes.

Clonal differences in leaf and pod resistance at the post-penetration stage of infection. The clonal differences in leaf and pod resistance at the post-penetration stage of infection are shown in Table 1. Lesion sizes obtained from the punchinoculation tests of leaf varied significantly $(\mathrm{P}<$ 0.001 ) among the genotypes. SCA 6 produced the smallest lesions, while lesions were significantly large on MO 20, T79/ 501, VENC 44, EQX 78 and PA 120 and intermediate on PA 107, ICS43, IFC 5, BE 10, EQX 3360-3, LECTEEN $37 \mathrm{f}$ and LECTEEN $37 \mathrm{i}$.

A highly significant difference $(\mathrm{P}<0.001)$ was also observed among genotypes for pod resistance to $P$. palmivora invasion based on size of lesions (Table 1). Significantly smaller lesions were recorded on SCA 6. Lesions on LAF 1, T85/799, GU225V, and ICS1 were moderate; but significantly larger lesions were produced on the rest of the genotypes. 
Two distinct patterns of spread of lesions were observed among the genotypes (data not shown). In genotypes with relatively small lesions, such as SCA 6, necrosis was restricted predominantly within the mesophyll. On the contrary, rapid spread of lesions through both mesophyll and veins was observed in MO 20, and T79/501 resulting in very large lesions.

Clonal differences in resistance scores of leaf disc tests and field infection of P. palmivora. Results of clonal differences in resistance scores of leaf disc tests and field infection of $P$. palmivora are shown in Table 2. Disease severity scores on leaf discs of the 25 cacao genotypes inoculated with $P$. palmivora were highly significant $(\mathrm{P}<0.001)$ among some genotypes. The disease severity scores varied from 0.96 for SCA 6 to 4.28 for MO 20.

Field resistant levels of the 25 genotypes to P. palmivora were significantly different $(\mathrm{P}<$ 0.001) (Table 2). The resistant genotypes were SCA 6, T85/799 and IFC 5. The moderately resistant genotypes were EET59H, PA 107 and GU 225V; while the susceptible genotypes were PA120, MOCORONGO, LECTEEN 37f, ICS 43, SPEC 54i, EQX 78, LECTEEN 37f, LAF 1, AMAZ 15-15, EQX 3360-3, IMC 47, PA 150, UF 676, VENC4-4, ICS 1, BE 10, MO 20, MAN 15-2 and T79/501.

TABLE 2. Clonal differences in leaf disc test and natural field infection of cocoa

\begin{tabular}{|c|c|c|c|c|c|c|c|}
\hline \multirow[t]{2}{*}{ Clones } & \multicolumn{3}{|c|}{ Mean leaf disc score(LDS) } & \multirow{2}{*}{$\begin{array}{c}\text { Mean of } \\
\text { LDS trials } \\
\text { M1 }\end{array}$} & \multicolumn{2}{|c|}{ Mean of months of field infection } & \multirow{2}{*}{$\begin{array}{l}\text { Mean of years } \\
\text { of field infection } \\
\text { M2 }\end{array}$} \\
\hline & Trial 1 & Trial 2 & Trial 3 & & 2007 & 2008 & \\
\hline PA120 & 4.06 & 3.82 & 3.36 & 3.75 & 38.4 & 10.2 & 24.30 \\
\hline MOCORONGO & 3.64 & 3.44 & 2.94 & 3.34 & 32.2 & 32.4 & 32.30 \\
\hline LECTEEN 37i & 3.10 & 3.04 & 2.88 & 3.01 & 37.7 & 33.3 & 35.50 \\
\hline $\operatorname{ICS} 43$ & 3.18 & 3.08 & 2.54 & 2.93 & 46.8 & 33.9 & 40.35 \\
\hline SPEC 54i & 3.54 & 3.28 & 3.12 & 3.31 & 28.7 & 32.5 & 30.60 \\
\hline EQX 78 & 3.62 & 3.54 & 2.90 & 3.35 & 31.2 & 32.1 & 31.65 \\
\hline EET $59 \mathrm{H}$ & 2.00 & 1.96 & 1.86 & 1.94 & 19.7 & 15.2 & 17.45 \\
\hline PA107 & 2.10 & 2.32 & 2.48 & 2.30 & 14.5 & 15.1 & 14.80 \\
\hline LECTEEN $37 f$ & 3.18 & 3.02 & 2.70 & 2.97 & 30.7 & 22.0 & 26.35 \\
\hline SCA 6 & 0.96 & 1.08 & 1.20 & 1.08 & 3.2 & 3.4 & 3.30 \\
\hline LAF 1 & 1.58 & 1.58 & 1.68 & 1.61 & 52.6 & 16.5 & 34.55 \\
\hline T85/799 & 1.32 & 1.54 & 1.52 & 1.46 & 5.0 & 6.1 & 5.55 \\
\hline AMAZ 15-15 & 3.60 & 3.44 & 2.74 & 3.26 & 30.9 & 32.3 & 31.60 \\
\hline EQX 3360-3 & 2.70 & 2.70 & 2.84 & 2.75 & 44.8 & 47.3 & 46.05 \\
\hline IFC 5 & 2.20 & 2.16 & 1.96 & 2.11 & 9.5 & 22.8 & 16.15 \\
\hline IMC 47 & 3.62 & 3.32 & 2.98 & 3.31 & 37.6 & 28.2 & 32.90 \\
\hline PA150 & 3.48 & 3.42 & 3.88 & 3.59 & 63.7 & 46.5 & 55.10 \\
\hline UF 676 & 3.14 & 3.20 & 2.98 & 3.11 & 46.8 & 33.8 & 40.30 \\
\hline VENC4-4 & 3.90 & 3.68 & 3.92 & 3.83 & 53.5 & 46.2 & 49.85 \\
\hline ICS 1 & 1.52 & 1.42 & 1.54 & 1.49 & 32.3 & 27.2 & 29.75 \\
\hline BE 10 & 2.92 & 3.12 & 3.00 & 3.01 & 44.1 & 42.6 & 43.35 \\
\hline MO 20 & 4.28 & 4.02 & 4.12 & 4.14 & 48.2 & 48.8 & 48.50 \\
\hline MAN 15-2 & 3.40 & 3.30 & 2.88 & 3.19 & 28.7 & 14.9 & 21.80 \\
\hline GU 225V & 1.48 & 1.60 & 1.52 & 1.53 & 12.1 & 14.8 & 13.45 \\
\hline T79/501 & 4.06 & 3.80 & 3.98 & 3.95 & 49.4 & 12.5 & 30.95 \\
\hline $\operatorname{LSD}(P<0.05)$ & 0.21 & 0.23 & 0.36 & & 22.7 & 16.40 & \\
\hline CV (\%) & 3.58 & 4.08 & 6.64 & & 59.0 & 36.4 & \\
\hline
\end{tabular}


Relationship between detached leaf tests and detached pod tests at both penetration and postpenetration stages of infection. The relationship between detached leaf tests and detached pod tests at both penetration and post-penetration stages of infection are shown in Table 3 . Number of lesions on leaves and pods showed positive and significant correlation $(\mathrm{r}=0.881$ and $\mathrm{P}<0.001)$ at the penetration level of infection. Also, leaf lesion size and pod lesion size had a positive and significant correlation $(r=0.898 ; \mathrm{P}<0.001)$ at the post-penetration levels of infection. Similarly, leaf disc score and penetration and post-penetration reactions of pod to Phytophthora infection was positive and significant $(\mathrm{r}=0.932, \mathrm{P}<0.001$; and $\mathrm{r}=0.846$ and $\mathrm{P}<0.001$; respectively).

Relationship between detached leaf tests and natural field infection of Phytophthora. The relationships between detached leaf tests and natural field infection of pods by Phytophthora are shown in Table 3. Results of the reaction of leaves at the penetration and post-penetration levels show a significant correlation $(r=0.482, P$ $=0.025$; and $\mathrm{r}=0.612, \mathrm{P}=0.001$, respectively) with the average of natural field infection by Phytophthora pod rot in the years of 2007 and 2008. A positive and highly significant correlation
(0.677, $\mathrm{P}=0.001$ ) was also obtained between leaf disc tests and the average of field infection in 2007 and 2008.

Relationship between detached pod tests and natural field infection of Phytophthora. The relationship between detached pod tests and natural field infection of pods by Phytophthora are shown in Table 3. Results of the reaction of pods at the penetration level show a correlation $(r=0.616$ and $\mathrm{P}=0.001$ ) with the average of field infection. A correlation coefficient of $r=0.412$ (P $=0.017$ ) was obtained between the reaction of pods at the post-penetration level of infection and the average of field infections.

Repeatability of leaf disc test and natural field infection. Table 3 shows the correlation coefficients of the three trials of leaf discs inoculated with $P$. palmivora. A high correlation coefficient $(\mathrm{r}=0.971, \mathrm{P}=0.000)$ was obtained between the results of trial 1 and trial 2. Similarly, high correlation coefficient values were obtained between trial 1 and trial $3(\mathrm{r}=0.947, \mathrm{P}=0.000)$, and trial 2 and trial $3(\mathrm{r}=0.913, \mathrm{P}=0.000)$. There was no significant correlation $(\mathrm{r}=0.492, \mathrm{P}=0.05)$ between results of natural field infection in 2007 and field infection in 2008.

TABLE 3. Coefficients of correlation ( $r$ ) among results of the six screening methods of Phytophthora palmivora resistance in 25 cocoa clones

\begin{tabular}{|c|c|c|}
\hline Results of screening methods & r & Level of significance \\
\hline Lesion number on pods versus lesion number on leaf & 0.911 & *** \\
\hline Lesion size on pods versus lesion size on leaf & 0.898 & $* \star *$ \\
\hline M1 versus lesion number on leaf & 0.864 & 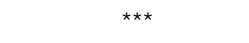 \\
\hline M1 versus lesion number on pod & 0.932 & *** \\
\hline M1 versus lesion size on leaf & 0.963 & $* * \star$ \\
\hline M1 versus lesion size on pod & 0.846 & *** \\
\hline M2 versus lesion number on leaf & 0.482 & NS \\
\hline M2 versus lesion number on pod & 0.616 & ** \\
\hline M2 versus lesion size on leaf & 0.612 & ** \\
\hline M2 versus lesion size on pod & 0.412 & NS \\
\hline $\mathrm{M} 2$ versus $\mathrm{M} 1$ & 0.677 & $* * *$ \\
\hline Trial 1 versus trial 2 of leaf disc score & 0.971 & *** \\
\hline Trial 1 versus trial 3 of leaf disc score & 0.947 & 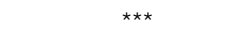 \\
\hline Trial 2 versus trial 3 of leaf disc score & 0.913 & $* \star *$ \\
\hline 2007 versus 2008 field infection of Phytophthora & 0.492 & NS \\
\hline
\end{tabular}

Significant at ${ }^{* * *} 0.1 \%$; $* \star 1 \%$; NS, Not significant at $5 \% . M 1=$ Mean of LDS trials; $M 2=$ Mean of years of field infection 


\section{DISCUSSION}

In an attempt to minimise environmental influences and to observe the true resistance level of the cocoa genotypes, resistance evaluation trials were conducted in two environments, in the field and in the laboratory. With all the genotypes planted under the same environmental conditions, the observed variations could probably be genetic. Tan and Tan (1990) and Simmonds (1994) observed similar variations in their studies on the resistance of cacao progenies to $P$. palmivora. Such large genetic variations have been noted by Nyasse et al. (1994), Blaha and Latode (1997) and Iwaro et al. (2005) who reported significant differences among cacao genotypes after inoculation of detached pods with $P$. palmivora.

Previous investigations had shown that stomata on cacao leaves could serve as infection courts to Crinipellis perniciosa, the pathogen of Witche's-broom disease and more recently to $P$. palmivora (Iwaro, 1995). It is possible that some of these factors could be responsible for differences in clonal reaction of leaf and pod to infection at the penetration stage.

In a study of the modes of resistance of cacao to $P$. palmivora infection, Iwaro (1995) concluded that resistance operates at two distinct stages of infection, the penetration stage, which restricts the entry and establishment of the pathogen, thus reducing the frequency of lesions; and the postpenetration stage, which reduces the rate of spread of the pathogen and hence the rate of lesion expansion. The distribution of genotypes into the various levels of resistance at the penetration and post-penetration stages of infection suggests that penetration and postpenetration inoculation of leaves and pods can effectively discriminate between the levels of resistance of genotypes.

The significant correlation between number of lesions on leaves and that on pods suggests that the resistance mechanisms operative at the penetration stage of infection in both leaf and pod may be alike. The observed similarity between the resistant levels to Phytophthora of cacao genotypes inoculated either by detached pod or detached leaf method suggests that either screening method could be used for the screening of resistance against black pod disease of cacao. This eliminates the need to wait until cocoa varieties mature and bear pods before their disease resistance levels can be screened. Resistance of leaves at the penetration stage of infection can, therefore, be used to predict pod resistance. This finding is contrary to that of Iwaro et al. (1997) who observed poor correlation between penetration resistance in leaf and pod. They suggested that since Phytophthora infects both leaf and pod, resistance in leaf and pod at the penetration level of infection could complement each other.

The high positive correlation obtained between pod and leaf resistance at the postpenetration stage of infection suggests that the mechanism conferring post-penetration resistance within leaf and pod could be inherent. The occurrence of such a characteristic of cacao leaf suggests the possibility of the use of leaves of cacao seedlings for the prediction of pod resistance to the black pod disease. This observation conforms with findings of Iwaro et al. (1997), who observed high positive correlation between leaf and pod at the post-penetration stage of infection.

The differences among genotypes at the postpenetration levels as reflected in sizes and patterns of spread of lesions (Plates 1) could be due to presence of some biochemical factors. Spence (1961) indicated the involvement of oxidizable phenols and polyphenol oxidase activity in determining lesion size in cacao.

The significant differences among the genotypes of cacao in reactions to $P$. palmivora and the distribution of scores for resistance to $P$. palmivora from serial trials indicate that the leaf disc test effectively discriminated the various levels of resistance in the 25 cacao accessions assessed in this study. A similar conclusion was made by several other workers (Nyasse et al., 1995; Tondge et al., 1998; Tahi et al., 2006).

The positive correlation between leaf disc scores and lesion number on size of pods suggests that the forms of resistance assessed by leaf disc test and detached pod test at the penetration and post-penetration levels are inherent. Such a characteristic of cacao leaf discs 
suggests the possibility of the use of leaf discs of cacao seedlings for the screening of pod resistance to the black pod disease of cacao.

The high correlation of leaf disc test with field infections suggests that prediction of pod resistance to Phytophthora infection in the field could be made from laboratory inoculation of leaf discs. A similar observation was reported by Nyasse et al. (2002) in Cameroon and by Tahi et al. (2006) in Cote d'Ivoire, who found that when field or nursery leaves of clones were inoculated at the hardening stage, the results correlated with natural field infection of pods with P. palmivora.

The higher correlation coefficient of leaf disc test with detached pod tests at penetration and post-penetration stages of infection, and natural field infection of pods by $P$. palmivora, than the other screening methods suggests its effectiveness and reliability in screening resistance levels of cocoa genotypes to $P$. palmivora. The high correlation between the serial trials of leaf disc test suggests that results of leaf disc test are repeatable.

The significant correlation between the detached pod test at the penetration and postpenetration stages of infection, and the average of 2 years field infection suggests the usefulness of the detached pod test as an effective method of assessing clonal resistance to Phytophthora pod rot and predicting field reaction in the long term. Since field observations are labour-intensive and expensive to conduct on yearly basis, the detached pod test offers a more feasible and effective means of assessing clonal resistance to Phytophthora pod rot. Being a non-destructive inoculation method, the detached pod test provides a suitable option for assessment of cocoa collections in genebanks. Iwaro and Singh (2004) and Efombagn et al. (2004) reported a similar observations in studies on the relationship between detached pods and field infection of Phytophthora.

Also, the significant correlation between detached leaf test at the penetration and postpenetration stages of infection and field infection suggests that field resistance to Phytophthora infection on mature fruits could be reliably evaluated by intrinsic resistance of cacao leaf tissue to $P$. palmivora infection at the penetration and post-penetration levels of infection. Iwaro et al. (1997) noted a similar association between the reaction of detached leaves and attached pods to Phytophthora palmivora infection. The poor relationship between field infections in 2007 and 2008 indicates variations in environmental factors in the field.

\section{CONCLUSION}

Overall, for the convenience of operation and reliability of results, leaf disc test appears to be the best, and is also time saving. With adequate standardisation of the environment, it is likely that the leaf discs are faced only with the Phytophthora infection and are not adversely affected by other factors that could confound the results. In the pod inoculation, there is possibility of dripping of zoospores and in the natural field infection, environmental factors cannot be controlled and possibility of disease escape is high.

\section{ACKNOWLEDGEMENTS}

We thank the Common Fund for Commodities (CFC) for financial support. Our sincere gratitude goes to the technical staff of Plant Pathology Division, CRIG, for help in this study.

\section{REFERENCES}

Adomako, B. 2006. Combining ability analysis of black pod disease incidence in cocoa genotypes in Ghana. Tropical Science 46: 201-204.

Adomako, B. 2007. Causes and extent of yield losses in cocoa progenies. Tropical Science 47: 22-25.

Anon. 1995. Pest and disease. In: Report on recent decline in cocoa production in Ghana and measures to revamp the industry. Government of Ghana, Accra, Ghana. pp. 4344.

Efombagn, M.I.B., Marelli J.P., Ducamp, M., Cilas, C., Nyasse, S. a nd Vefonge, D. 2004. Effect of fruiting traits on the field resistance of cocoa (Theobroma cacao L.) clones to Phytophthora megakarya. Journal of Phytopathology 152:557-562. 
Evans, H.C. and Prior, C. 1987. Cocoa pod diseases: causal agents and control. Outlook on Agriculture 16:35-41.

Greathouse, D. C., Laetsch, W. M., and Phinney, B. O. 1991. The shoot-growth rhythm of a tropical tree (Theobroma cacao L.). American Journal of Botany 58:281-286.

Iwaro, A.D. and Singh, V. 2004. Progress report on the germplasm enhancement programme for resistance to black pod disease. In: Annual Report for 2003. Cocoa Research Unit, The University of the West Indies, St. Augustyine, Trinidad. pp. 43-45.

Iwaro, A.D., Screenivasan, T.N. and Umaharan, P. 1997a. Foliar resistance to Phytophthora palmivora as an indicator of pod resistance in Theobroma cacao. Plant Disease 81:619624.

Iwaro, A.D., Umaharan, P. and Screenivasan T.N. 1997b. Inheritance of foliar resistance to Phytophthora palmivora (Butler) Butler in cacao (Theobroma cacao L.). Euphytica 96: 377-383.

Iwaro, A.D., Umaharan P., Screenivasan, T.N. 1999. Inheritance of foliar resistance to Phytophthora palmivora (Butler) Butler in cacao (Theobroma cacao L.). Euphytica 96: 377-383.

Iwaro, A.D., Thevenin, J.M., Butler, D.R. and Eskes, A.B. 2005. Usefulness of the detached pod test for assessment of cacao resistance to Phytophthora pod rot. European Journal of Plant Pathology 113:173-182.

Kebe, B.I., N’Goran, J.A.K., Tahi, G.M., Paulin, D., Clement, D., Eskes, A.B. 1999. Pathology and breeding for resistance to black pod in Cote d'Ivoire. In: Proceedings of the International Workshop on the Contribution of Disease Resistance to Cocoa Variety Improvement, Salvador, Bahia, Brazil, 24-26 November 1996. International Group for Genetic Improvement of Cocoa (INGENIC). pp. 135-140.

Nyasse, S., Blaha G. and Cilas, C. 1994. Pathogenie de Phytophthora megakarya et son implication pour la mise an point d'un test precose de sensibilite a la pourriture brune sur cacaoyer. In: Proceedings of the $11^{\text {th }}$ International Cocoa Research Conference, 18-24 July 1993, Yamoussoukro Cote
d'Ivoire. Cocoa Producers Alliance, Lagos, Nigeria. pp. 83-90.

Nyasse, S., Cilas C., Herail, C. and Blaha, G. 1995. Leaf inoculationas an early screening test for cocoa (Theobroma cacao L.) resitance to Phytophthora black pod disease. Crop Protection 14:657-663.

Nyasse, S., Despreau, D. and Cilas, C. 2002. Validity of a leaf inoculation test to assess the resistance to Phytophthora megakarya in cocoa (Theobroma cacao L.) diallel mating design. Euphytica 123:395-399.

Okey, E.N.1996. Histopathological and biochemical studies on cacao (Theobromacacao L.) canker caused by Phytophthora palmivora (Butler) Butler. Ph.D. thesis. The University of the West Indies, Trinidad and Tobago.

Opoku, I.Y., Assuah, M.K. and Aneani, F. 2007. Management of black-pod disease of cocoa with reduced number of fungicide application and crop sanitation. African Journal of Agricultural Research 2:601-604.

Screenivasan, T. N. 1995. A rapid method of inoculation of Phytophthora palmivora (Butler) Butler on attached pods. In: The $9^{\text {th }}$ Proceedings of the International Cocoa Research Conference. pp. 293-302.

Simmonds, N.W. 1994. Horizontal resistance to cocoa diseases. Cocoa Growers Bulletin 47: 42-53.

Sitapai, E. C. 1989. Studies on the resistance in cocoa (Theobroma cacao L.) to Phytophthora palmivora (Butler) Butler. M. Phil. Thesis. The University of the West Indies. Trinidad and Tobago.

Spence, J.A. 1961. Black pod disease of cocoa II: A study in host-parasite relations. Annals of Applied Biology 49:723-734.

Tahi, G.M. 2003. Evaluation sur Feuilles de Cacaoyer (Theobroma cacao L.) de la Resistance a Phytophthora palmivora (Butler) Butler, Agent de la Pourriture Brune des Cabosses: Influence de Certains Facteus et Etude de l'Heritabilite du caractere. Abidjan, Cote d'Ivoire: Universite de Cocody, Ph.D Thesis.

Tahi, G.M., Kebe, B.I., N’Goran, J.A.K., Sangare, A., Mondeil, F., Cilas, C. and Eskes, A.B. 2006. Expected selection efficiency for resistance 
to cacao pod rot (Phytophthora palmivora) comparing leaf disc inoculations with field observations. Euphytica 149:35-44.

Tan, G.Y. and Tan, W.K. 1990. Additive inheritance of resistance to pod rot caused by Phytophthora palmivora in cocoa. Theor Appl. pp. 32-46.

Tondje, P.R., Bakala, J., Partiot, M. and Mouen Bedimo, J.A. 1988. Essai de mise au point d'un test de vis de Phytophthora sp. In: Proceedings of the $10^{\text {th }}$ International Cocoa
Research Conference, Santo Domingo, Dominican Republic, 17-23 May 1987.Cocoa Producers'Alliance, Lagos , Nigeria. pp. 413419.

Wheeler, B.E. J. 1992. Assessment of resistance to major cocoa diseases. In: Proceedings of the International Workshop on Conservation, Characterization and Cocoa Genetic Resources in the $21^{\text {st }}$ Century. Cocoa Res. Unit, University of the West Indies, Trinidad and Tobago. pp. 139-145. 